\title{
Polyunsaturated fatty acid concentrations in human hindmilk are stable throughout 12-months of lactation and provide a sustained intake to the infant during exclusive breastfeeding: an Italian study
}

\author{
Franca Marangoni $^{1 *}$, Carlo Agostoni ${ }^{2}$, Anna M. Lammardo ${ }^{2}$, Marcello Giovannini $^{2}$, Claudio Galli $^{1}$ \\ and Enrica Riva ${ }^{2}$ \\ ${ }^{1}$ Institute of Pharmacological Sciences, University of Milan, 9 Via Balzaretti, 20133 Milan, Italy \\ ${ }^{2}$ Department of Paediatrics, San Paolo Hospital, University of Milan, 8 Via A di Rudini, 20142 Milan, Italy
}

(Received 30 October 1998 - Revised 9 November 1999 - Accepted 8 December 1999)

\begin{abstract}
While a wealth of data on the fatty acid composition of mature human milk has been published, limited information is available on the quantities of individual fatty acids supplied to the suckling infant with maternal milk, through the whole first year of life. Our aim was to qualitatively and quantitatively evaluate the fatty acid composition of human milk from Italian mothers, throughout extended lactation with particular emphasis on the long-chain polyunsaturated fatty acids. We have thus measured the total fat content and the concentrations of major fatty acids by quantitative GLC in pooled breast hindmilk collected from all feedings over $24 \mathrm{~h}$ at colostrum, $1,3,6,9$ and 12 months in ten mothers recruited after delivery of full-term infants. Total saturated fatty acids progressively increase and total monounsaturated progressively decrease as percentage levels, while among long-chain polyunsaturated fatty acids, percentages of arachidonic acid and docosahexaenoic acid decrease from colostrum up to the third month. Hindmilk total lipids $(\mathrm{mg} / \mathrm{dl})$ rise more than twofold up to 3 months, and then remain stable. The amounts $(\mathrm{mg} / \mathrm{dl})$ of linoleic acid and $\alpha$-linolenic acid progressively increase, following the trend of total fat, while arachidonic and docosahexaenoic concentrations $(\mathrm{mg} / \mathrm{dl})$ remain stable throughout the whole nursing period. Assessment of the intakes per $\mathrm{kg}$ body weight shows different trends for the individual major long-chain polyunsaturated fatty acids supplied to the infant from hindmilk during exclusive breast-feeding ( 3 months). This information may be useful for the evaluation of infant intakes during extended lactation.
\end{abstract}

Human milk lipids: Docosahexaenoic acid: Infant nutrition

Human milk represents the ideal source of nutrients for the newborn. Its unique composition has been associated with the favourable developmental outcomes observed in subjects who had been fed maternal milk (Lucas et al. 1992).

Long-chain polyunsaturated fatty acids (FA) are present in primate milk and especially in human milk in concentrations greater than in other commercially available milks, such as bovine milk (Jensen et al. 1990). This is biologically relevant since the two major long-chain polyunsaturated FA, arachidonic acid (20:4n-6) and docosahexaenoic acid (22:6 $n$-3) accumulate in brain during the early period of postnatal development when milk represents the only source of fat. It has been shown that, during the first months of extrauterine life, breast-fed infants accumulate higher amounts of docosahexaenoic acid in the brain cortex than infants fed standard formulas lacking 22:6n-3 (Farquharson et al. 1992). In order to mimic the conditions of breast-fed infants, different mixtures and sources of long-chain polyunsaturated FA are being used by formula producers (Koletzko, 1997). The functional effects of these modifications are still under investigation (Agostoni et al. 1995). So far, studies focusing on the FA of human milk lipids indicate changes in percentage levels of most long-chain polyunsaturated FA from colostrum up to mature milk (Gibson \& Kneebone, 1981; Clark et al. 1982; Boersma et al. 1991; Luukkainen et al. 1994; Makrides et al. 1995). It would appear that information on the absolute amounts of longchain polyunsaturated FA present in milk at different stages of lactation are important for the assessment of the physiological intakes by the infant. Since few studies include data on the lipid composition and the amounts of FA supplied to the infants through lactation, the need for detailed investigations covering extended periods of lactation on a worldwide basis has been recently stressed (Jensen, 1996). 


\section{Methods}

\section{Subjects}

The aim of the present study was to evaluate the FA composition and content in milk samples from at least ten mothers throughout a 12-month nursing period. Thus we recruited at delivery a sufficient number of mothers on the basis of the epidemiological data on the duration of the breast-feeding practice in our area (North-western Italy). According to an on-going epidemiological survey carried out by our department (Department of Paediatrics, San Paulo Hospital, Milan, Italy), this figure approaches $10 \%$ of the mothers who begin to breast-feed and are still giving at least one meal at the breast 12 months after delivery.

Mothers who gave birth to healthy, full-term infants (3742 weeks gestation) in our hospital (San Paulo Hospital) were eligible for entry into the study. Women suffering from any metabolic disorder (hyperlipidaemia, insulin-dependent diabetes) and/or taking corticosteroids during pregnancy were excluded. Mothers gave informed consent and the design was approved by the Institutional Ethical Committee.

\section{Breast-milk collection and analysis}

The original design provided consecutive $24 \mathrm{~h}$ collections of breast milk during the first day of nursing (colostrum), at the end of the first month, and at 3, 6, 9 and 12 months. All mothers in the study were encouraged to breast-feed for as long as possible and were instructed to express breast milk at the end of each feed (hindmilk) over a $24 \mathrm{~h}$ period into sterile vials. This collection method is least troublesome to mothers since it does not interfere with infant suction. To validate our findings a subsample of the mothers $(n 7)$ was required to collect fore-, midstream- and hindmilk during each suckling episode throughout $24 \mathrm{~h}$ at colostrum, 1 month and 3 months of lactation.

Maternal diets have been assessed by the use of validated food frequency questionnaires (Trevisan et al. 1992; Pisani et al. 1997) applied at 3-month intervals (1 day, 3, 6, 9, 12 months) in order to control for possible seasonal changes in dietary intakes. Mothers weighed their infants by means of electronic scales accurate to $\pm 5 \mathrm{~g}$ before and after each meal the day before the visit in order to quantify the milk intake. Breast-milk samples were frozen immediately after collection and delivered to us for analysis on the day immediately after milk collection when the subjects brought their infants for clinical examination. Aliquots from all meals collected on the same day were then pooled.

On the day of delivery of milk samples to the hospital, blood was drawn from fasting mothers at 1 day and 3 months, and frozen until analysed for the FA composition of plasma lipids.

Plasma and milk total lipids were determined gravimetrically after extraction with chloroform-methanol $(2: 1$, $\mathrm{v} / \mathrm{v})$ containing butylhydroxytoluene as antioxidant, according to the method of Folch et al. (1956).

Milk total cholesterol content was determined enzymatically (Boehringer ${ }^{\circledR}$ Mannheim GmbH, Mannheim, Germany). Milk phospholipids were quantified after assessment of inorganic phosphorus (Rouser et al. 1966) on the phospholipid fraction after separation by TLC on silica-gel-coated plates, using hexane-diethyl ether-acetic acid (70:30:1.5, by vol.) as mobile phase.

FA methyl esters from plasma and milk lipid extracts were prepared by acidic transmethylation using methanolic $3 \mathrm{M}-\mathrm{HCl}$ (Supelco, Belafonte, PA, USA) and they were separated by GLC (GC 85.10, DANI, Monza, Italy, equipped with a flame ionization detector) using a capillary column (SP-2560 Supelco ${ }^{\mathrm{TM}}$, $100 \mathrm{~m}$ length, $0.25 \mathrm{~mm}$ i.d., $0.2 \mathrm{~mm}$ film thickness) with programmed temperature (from 150 to $220^{\circ} \mathrm{C}$, with $1^{\circ} \mathrm{C} / \mathrm{min}$ increments up to $180^{\circ} \mathrm{C}$ and then $6^{\circ} \mathrm{C} / \mathrm{min}$ increments). The percentage distribution of FA methyl esters was determined by using an Autochrom 162 CSI (DANI) recording integrator, and the FA were quantified by addition to the sample of eptadecanoic acid (17:0) as internal standard before methyl ester preparation.

\section{Statistical analysis}

Mann-Whitney and Fisher exact tests were used to compare the basic characteristics of longer- and shorter-term lactating mothers. Friedman's test and ANOVA for repeatedmeasures were used to compare the individual FA levels (g FA as \% of total FA) and concentrations $(\mathrm{mg} / \mathrm{dl})$ at the different time points within the 12-month period (SPSS for Windows 5.0; SPSS Inc., Chicago, IL, USA), using Fisher test for post-hoc comparison of two different time points.

\section{Results}

Ninety-five mothers were recruited. Among them, ten mothers completed the follow-up of 12-month nursing. Their basic characteristics are described in Table 1 and socioeconomic indicators were coded according to the Italian Census (Central Statistics Institute (ISTAT), 1983). They did not differ from the other eighty-five mothers. There was only a trend towards a smaller presence of primiparous (although non-significant) in the ten mothers still breastfeeding at 12 months.

We have chosen to analyse hindmilk lipids, because it has been shown (Gibson \& Kneebone, 1980; Koletzko et al. 1986) that the percentage composition of human milk FA does not change during a single feed nor undergoes diurnal variation, while hindmilk has a higher total fat content (Herzer et al. 1983). This is shown in Table 2, which describes the fat contents of the various types of milk (foremilk, midstream milk and hindmilk) collected from seven mothers at the three time periods. It appears that the median fat content of hindmilk is higher than that of midstream milk, ranging from 25 to $37 \%$ (mean 24.8 to $31.7 \%$ ).

Table 3 describes the average composition of maternal diets throughout lactation over a 12-month period. The energy intake is within the range of the Italian recommended dietary allowances with a tendency to a higher intake in the first 3 months of lactation. In general the proportions of the various components of the diet (proteins, carbohydrates, lipids and FA classes) remain constant throughout the whole 12-month periods.

The relatively uniform fat intake during the study period may explain why the FA composition of plasma total lipids (Table 4) does not change significantly from day 1 to 3 months of lactation. It was not possible to obtain plasma 
Table 1. Basic characteristics of mothers breast-feeding up to 12 months $(n 10) v$. all the others initially recruited for the study ( $n 85$ )

(Median values and ranges)

\begin{tabular}{|c|c|c|c|c|}
\hline & \multicolumn{2}{|c|}{$\begin{array}{l}\text { Breast-feeding up } \\
\text { to } 12 \text { months }\end{array}$} & \multicolumn{2}{|c|}{$\begin{array}{l}\text { Not breast-feeding up } \\
\text { to } 12 \text { months }\end{array}$} \\
\hline & Median & Range & Median & Range \\
\hline Age at delivery (years) & 33.5 & $29.0-36.0$ & 32.0 & $21.0-42.0$ \\
\hline Gestational age (weeks) & 39.3 & $38.2-41.4$ & 39.5 & $37.4-41.4$ \\
\hline Height $(\mathrm{cm})$ & 160.5 & $150-176$ & 164 & $148-174$ \\
\hline Standard body weight $(\mathrm{kg})$ & 52 & $45-80$ & 55 & $45-70$ \\
\hline Intrapregnancy body-weight increment $(\mathrm{kg})$ & 12 & $4-15$ & 12 & $6-20$ \\
\hline Pre-pregnancy BMI & 20.4 & $18.4-27.2$ & 20.5 & $17.7-28.8$ \\
\hline End-pregnancy BMI & 25.5 & $22.7-32.8$ & 24.3 & $21.6-33.3$ \\
\hline Primiparous (yes, no) & \multicolumn{2}{|c|}{5,5} & \multicolumn{2}{|c|}{47,38} \\
\hline Education $(<14$ years, $>14$ years $)$ & \multicolumn{2}{|c|}{4,6} & \multicolumn{2}{|c|}{34,51} \\
\hline Social category (upper, lower) & \multicolumn{2}{|c|}{7,3} & \multicolumn{2}{|c|}{51,34} \\
\hline Smoking (yes, no) & \multicolumn{2}{|c|}{3,7} & \multicolumn{2}{|c|}{23,62} \\
\hline
\end{tabular}

Table 2. Total lipid content $(\mathrm{g} / \mathrm{dl})$ of different milk samples throughout the first months of lactation

(Median values and ranges for seven subjects)

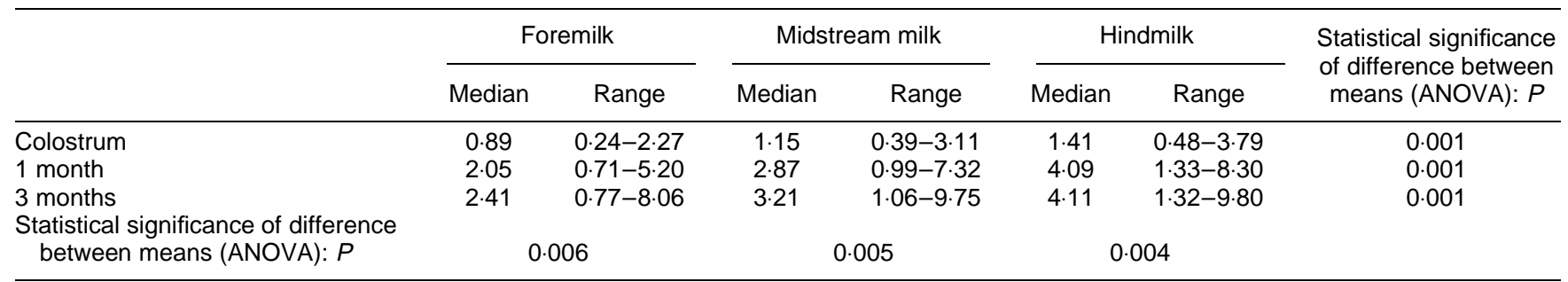

Table 3. Daily dietary intakes of energy and nutrients as percentage of total energy intake of lactating mothers throughout lactation (Mean values and standard deviations for ten subjects)

\begin{tabular}{|c|c|c|c|c|c|c|c|c|c|c|}
\hline & \multicolumn{10}{|c|}{ Time of lactation } \\
\hline & \multicolumn{2}{|c|}{$1 d$} & \multicolumn{2}{|c|}{3 months } & \multicolumn{2}{|c|}{6 months } & \multicolumn{2}{|c|}{9 months } & \multicolumn{2}{|c|}{12 months } \\
\hline & Mean & $\mathrm{SD}$ & Mean & SD & Mean & SD & Mean & SD & Mean & SD \\
\hline Energy (MJ) & $10 \cdot 73$ & 3.0 & 11.30 & 5.22 & 9.68 & 2.09 & 9.15 & 1.96 & 9.69 & 1.18 \\
\hline Proteins & $13 \cdot 7$ & $2 \cdot 4$ & $15 \cdot 3$ & 1.8 & $14 \cdot 1$ & 1.5 & $15 \cdot 1$ & 1.5 & $14 \cdot 7$ & 1.4 \\
\hline Carbohydrates & 49.2 & 7.5 & 50.6 & 7.8 & 48.2 & $6 \cdot 6$ & $45 \cdot 3$ & 7.0 & $48 \cdot 1$ & 4.5 \\
\hline Lipids & 36.9 & $7 \cdot 4$ & $35 \cdot 8$ & $8 \cdot 3$ & 38.7 & $5 \cdot 4$ & $40 \cdot 0$ & $6 \cdot 4$ & $37 \cdot 6$ & 4.2 \\
\hline Saturated & $12 \cdot 5$ & $3 \cdot 4$ & 12.5 & 3.4 & $12 \cdot 7$ & $2 \cdot 2$ & $14 \cdot 0$ & 3.2 & $12 \cdot 6$ & 1.8 \\
\hline Monounsaturated & $16 \cdot 4$ & 4.0 & $15 \cdot 6$ & 4.6 & $17 \cdot 4$ & 3.8 & $20 \cdot 7$ & 8.9 & $17 \cdot 1$ & $2 \cdot 1$ \\
\hline Polyunsaturated & 4.9 & 1.6 & 4.5 & 0.9 & $5 \cdot 2$ & 1.5 & $5 \cdot 6$ & $2 \cdot 0$ & $5 \cdot 7$ & $2 \cdot 1$ \\
\hline
\end{tabular}

samples at subsequent time points because of obvious ethical reasons.

The percentage composition of FA in milk lipids is reported in Table 5. Total saturated FA show an increasing trend mainly due to the doubling concentrations of myristic acid (14:0), while oleic acid (18:1n-9) decreases throughout extended lactation. 20:4 n-6 and 22:6n-3 levels significantly decrease in the first stage of lactation and the C18 precursors linoleic acid (18:2 n-6) and $\alpha$-linolenic acid $(18: 3 n-3)$ remain almost unchanged throughout the 12-month period. It is of interest that between colostrum and the first month of lactation there is a significant rise of $18: 3 n-6$, the product of $\Delta 6$ desaturation of $18: 2 n-6$, in association with the reduction of its elongation product, 20:2 n-6. All C20-24 unsaturated FA (including both the mono- and the polyunsaturated compounds, except eicosapentaenoic acid (20:5n-3, whose levels are very low) show a progressive percentage decrease throughout lactation.

Fig. 1 shows the pattern of total lipids, $18: 2 n-6,18: 3 n-3$, $20: 4 n-6$ and $22: 6 n-3$ concentrations (mg/dl) during the 12-month lactation. The total lipid content increases more than twofold within the first month of lactation. While $18: 2$ $n-6$ and 18:3n-3 steadily increase from colostrum up to 3 months (from 169 (SEM 41) to 390 (SEM 56) and from 9 (SEM 2) to 22 (SEM 3) mg/dl respectively), both $20: 4 n-6$ and $22: 6 n$-3 remain stable (from 15 (SEM 4) to 17 (SEM 2) and from 7 (SEM 1) to 8 (SEM 1) $\mathrm{mg} / \mathrm{dl}$ respectively) 
Table 4. Fatty acid composition (\%) of plasma total lipids at two stages of lactation

(Mean values and standard deviations for ten subjects)

\begin{tabular}{|c|c|c|c|c|}
\hline \multirow[b]{3}{*}{ Fatty acids } & \multicolumn{4}{|c|}{ Time of lactation } \\
\hline & \multicolumn{2}{|c|}{1 day } & \multicolumn{2}{|c|}{3 months } \\
\hline & Mean & SD & Mean & SD \\
\hline $14: 0$ & 0.91 & 0.55 & 1.43 & 0.61 \\
\hline $16: 0$ & 27.41 & $2 \cdot 22$ & 22.69 & $2 \cdot 61$ \\
\hline $18: 0$ & $6 \cdot 19$ & 1.74 & 8.56 & 1.72 \\
\hline $20: 0$ & 0.25 & 0.09 & 0.31 & 0.08 \\
\hline $22: 0$ & 0.54 & 0.17 & 0.66 & 0.16 \\
\hline $24: 0$ & 0.40 & 0.12 & 0.58 & 0.15 \\
\hline $16: 1 n-9$ & 1.87 & 0.61 & 1.91 & 1.06 \\
\hline $18: 1 n-9$ & 23.18 & $2 \cdot 79$ & $22 \cdot 60$ & 4.49 \\
\hline $18: 1 n-7$ & 1.58 & 0.25 & 1.70 & 0.28 \\
\hline $20: 1 n-9$ & $0 \cdot 18$ & 0.04 & 0.18 & 0.06 \\
\hline $22: 1 n-9$ & 0.04 & 0.01 & 0.05 & 0.02 \\
\hline $24: 1 n-9$ & 0.90 & 0.29 & 1.04 & 0.18 \\
\hline $20: 3 n-9$ & $0 \cdot 14$ & 0.06 & 0.15 & 0.04 \\
\hline $18: 2 n-6$ & 24.28 & $1 \cdot 70$ & 25.53 & $3 \cdot 15$ \\
\hline $18: 3 n-6$ & 0.21 & 0.08 & 0.39 & 0.09 \\
\hline $20: 3 n-6$ & 1.46 & 0.33 & 1.64 & 0.22 \\
\hline $20: 4 n-6$ & $7 \cdot 22$ & 0.89 & 7.55 & $1 \cdot 19$ \\
\hline $20: 4 n-6$ & 0.23 & 0.03 & 0.24 & 0.07 \\
\hline $22: 5 n-6$ & 0.34 & 0.04 & 0.18 & 0.03 \\
\hline $18: 3 n-3$ & 0.36 & 0.07 & 0.29 & 0.03 \\
\hline $20: 5 n-3$ & 0.32 & 0.09 & 0.29 & 0.08 \\
\hline $22: 5 n-3$ & 0.20 & 0.04 & 0.37 & 0.08 \\
\hline $22: 6 n-3$ & 1.80 & 0.24 & 1.65 & 0.26 \\
\hline Saturated & 35.70 & 0.90 & 34.24 & 1.60 \\
\hline Monounsaturated & $27 \cdot 75$ & $2 \cdot 63$ & 27.47 & 4.45 \\
\hline Polyunsaturated & 36.54 & 2.06 & 38.29 & $5 \cdot 80$ \\
\hline$n-3: n-6$ & 0.08 & 0.01 & 0.08 & 0.02 \\
\hline
\end{tabular}

throughout the study period. The amounts of $20: 5 n-3$ (not shown) range from $0.6(\mathrm{SEM} \mathrm{0.2)} \mathrm{to} 1.4(\mathrm{SEM} \mathrm{0.2)} \mathrm{mg} / \mathrm{dl}$ from 1- to 12-month lactation respectively.

The phospholipid : total lipid and especially cholesterol: total lipid ratios, represented in Fig. 2, significantly decrease throughout extended lactation. Table 6 reports the ranges of the daily intakes of lipids and of the major long-chain polyunsaturated FA per kg body weight at the beginning of lactation (colostrum) and after 1 and 3 months of exclusive breast-feeding. Since the data obtained for the ten long-term lactating mothers concern only hindmilk, we have calculated the range of fat concentration in foremilk on the basis of the lipid distribution in fore-, midstream- and hindmilk observed at the three time points in seven mothers out of the ninety-five recruited at the beginning of the study. By attributing to the midstream milk $100 \%$ of fats (Herzer et al. 1983) we have found that foremilk and hindmilk contribute $70 \%$ and $132 \%$ respectively of fat concentration of the midstream milk (median values). The daily intakes of lipids and phospholipids per $\mathrm{kg}$ body weight increase more than 5-fold from colostrum up to 1 month, while cholesterol is steadly supplied to the infant throughout the first 3 months of life. The polyunsaturated FA intakes increase with much greater increments for the $\mathrm{C} 18$ than for the $\mathrm{C} 20$ compounds up to 1 month. There is then a slight reduction of total lipids,

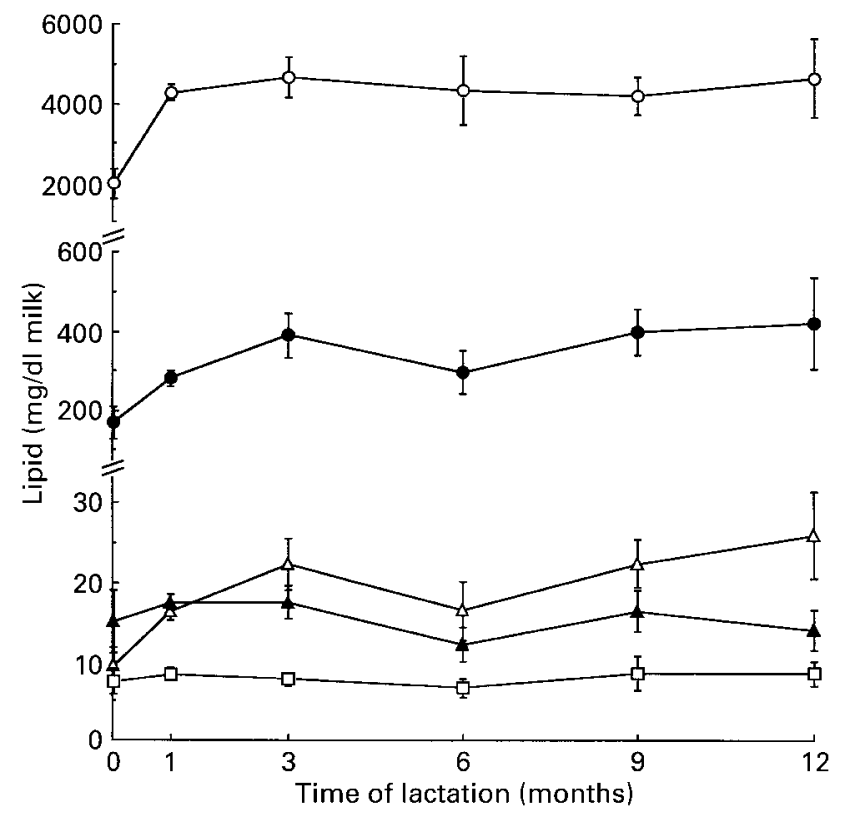

Fig. 1. Changes in the absolute amounts of total lipids in hindmilk throughout a 12-month lactation in ten subjects. $(O)$, Total lipids $(F$ 2.899, $P=0.002) ;(\bullet), 18: 2 n-6$ ( $F 2.741, P=0.03) ;(\triangle), 18: 3$

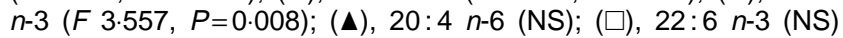
(ANOVA). Values are means with standard errors of the means represented by vertical bars.

phospholipids and long-chain polyunsaturated FA between 1 and 3 months, reaching colostrum levels, while their precursors, $18: 2 n-6$ and $18: 3 n-3$ are supplied to the infant in a constant manner through mature milk.

\section{Discussion}

To our knowledge this is the first Italian report on a complete qualitative and quantitative FA analysis of human milk at various stages of nursing in a homogeneous group of ten mothers from the first day of colostrum up to 12 months. In

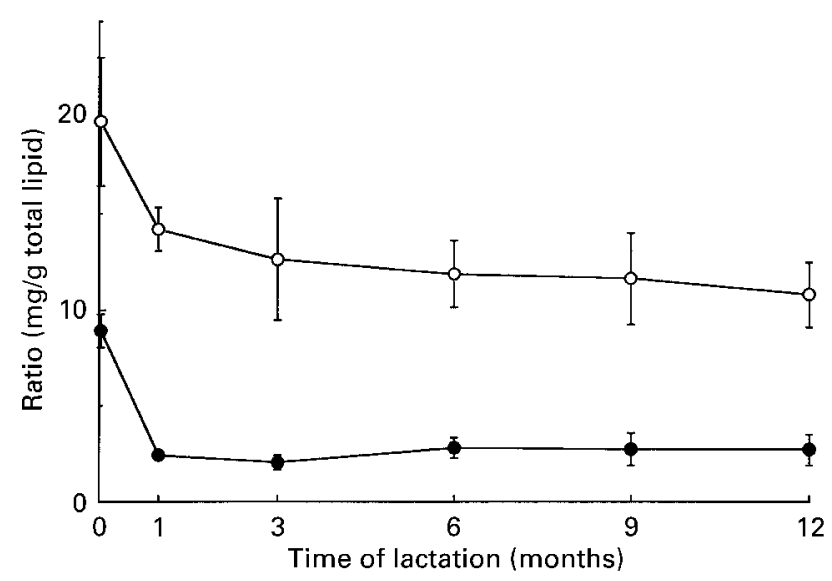

Fig. 2. Changes in the cholesterol : total lipid $((\bullet), F 22.77, P<0.0001$, ANOVA) and phospholipid : total lipid ((O) ratios, $F 2.487, P<0.04$, ANOVA) throughout a 12-month lactation in ten subjects. Values are means with standard errors of the means represented by vertical bars. 
Table 5. Fatty acid composition (\%) of milk total lipids during lactation (Mean values and standard deviations for ten subjects)

\begin{tabular}{|c|c|c|c|c|c|c|c|c|c|c|c|c|c|}
\hline \multirow[b]{3}{*}{ Fatty acids } & \multicolumn{12}{|c|}{ Time of lactation } & \multirow{3}{*}{$\begin{array}{l}\text { Statistical significance } \\
\text { of difference between } \\
\text { means (ANOVA) : } P \leqslant\end{array}$} \\
\hline & \multicolumn{2}{|c|}{$1 \mathrm{~d}$} & \multicolumn{2}{|c|}{1 month } & \multicolumn{2}{|c|}{3 months } & \multicolumn{2}{|c|}{6 months } & \multicolumn{2}{|c|}{9 months } & \multicolumn{2}{|c|}{12 months } & \\
\hline & Mean & SD & Mean & $\mathrm{SD}$ & Mean & SD & Mean & SD & Mean & SD & Mean & $\mathrm{SD}$ & \\
\hline $14: 0$ & $4 \cdot 34$ & 1.64 & $5 \cdot 79$ & 1.95 & 5.81 & $1 \cdot 27$ & $8 \cdot 38^{*}$ & $2 \cdot 31$ & $9 \cdot 38$ & $1 \cdot 76$ & 8.68 & 1.66 & 0.05 \\
\hline $16: 0$ & 25.71 & $2 \cdot 36$ & 25.49 & 1.45 & 25.03 & 2.27 & $25 \cdot 62$ & $2 \cdot 80$ & 24.53 & $2 \cdot 70$ & 24.27 & 1.78 & - \\
\hline $18: 0$ & $7 \cdot 38$ & $2 \cdot 14$ & 7.59 & $2 \cdot 28$ & $7 \cdot 71$ & 3.17 & 8.46 & 2.56 & 8.49 & 1.55 & 8.65 & $2 \cdot 85$ & - \\
\hline $20: 0$ & $0 \cdot 30$ & 0.21 & 0.31 & 0.20 & $0.19^{*}$ & 0.03 & 0.22 & 0.06 & 0.23 & 0.07 & 0.22 & 0.05 & 0.05 \\
\hline $22: 0$ & $0 \cdot 12$ & 0.04 & 0.12 & 0.04 & 0.10 & 0.03 & $0 \cdot 12$ & 0.04 & 0.09 & 0.05 & 0.14 & 0.08 & - \\
\hline $24: 0$ & 0.21 & 0.15 & $0 \cdot 16$ & 0.11 & $0.05^{*}$ & 0.03 & 0.08 & 0.06 & $0 \cdot 10$ & $0 \cdot 10$ & $0 \cdot 10$ & 0.05 & 0.05 \\
\hline $16: 1 n-9$ & $2 \cdot 25$ & 0.49 & 2.41 & 0.68 & $2 \cdot 59$ & 0.50 & $2 \cdot 17$ & 0.50 & $2 \cdot 18$ & 0.64 & 2.43 & 1.39 & - \\
\hline $18: 1 n-9$ & 38.08 & 4.52 & 41.69 & 3.26 & $40 \cdot 35$ & 4.50 & $37 \cdot 19^{*}$ & 5.03 & 37.08 & 3.27 & 34.69 & 3.70 & 0.05 \\
\hline $18: 1 n-7$ & $3 \cdot 18$ & 1.35 & 2.50 & 0.71 & 2.85 & 1.67 & 2.07 & 0.47 & 2.22 & 0.26 & 3.56 & $2 \cdot 13$ & - \\
\hline $20: 1 n-9$ & 1.00 & 0.25 & $0.49^{*}$ & 0.18 & 0.43 & 0.10 & 0.41 & 0.08 & 0.39 & 0.07 & 0.43 & 0.40 & 0.05 \\
\hline $22: 1 n-9$ & 0.22 & 0.08 & $0.10^{*}$ & 0.02 & 0.06 & 0.03 & 0.08 & 0.04 & 0.07 & 0.02 & 0.12 & 0.11 & 0.05 \\
\hline $24: 1 n-9$ & 0.31 & 0.16 & $0 \cdot 17^{*}$ & 0.11 & 0.10 & 0.05 & $0 \cdot 10$ & 0.06 & 0.09 & 0.06 & 0.17 & $0 \cdot 10$ & 0.05 \\
\hline $18: 2 n-6$ & 11.98 & 1.82 & $10 \cdot 16$ & 1.57 & $12 \cdot 08$ & 2.07 & 11.69 & $2 \cdot 12$ & $12 \cdot 64$ & 4.03 & 12.94 & 3.43 & 0.05 \\
\hline $18: 3 n-6$ & 0.07 & 0.04 & $0.12^{*}$ & 0.04 & 0.12 & 0.03 & 0.10 & 0.02 & 0.08 & 0.03 & 0.09 & 0.04 & 0.05 \\
\hline $20: 2 n-6$ & 0.98 & 0.26 & $0.42^{*}$ & 0.19 & 0.30 & 0.19 & 0.33 & 0.17 & 0.31 & 0.12 & 0.29 & 0.13 & 0.05 \\
\hline $20: 3 n-6$ & 0.72 & 0.14 & $0.52^{*}$ & 0.09 & 0.40 & 0.07 & 0.35 & 0.06 & 0.31 & 0.06 & 0.28 & 0.08 & 0.05 \\
\hline $20: 4 n-6$ & 1.05 & 0.26 & $0.64^{*}$ & 0.12 & 0.54 & 0.09 & 0.50 & 0.12 & 0.51 & $0 \cdot 10$ & 0.50 & $0 \cdot 10$ & 0.05 \\
\hline $22: 4 n-6$ & 0.49 & 0.27 & $0 \cdot 16^{\star}$ & 0.05 & 0.09 & 0.03 & 0.11 & 0.02 & 0.11 & 0.03 & 0.16 & 0.12 & 0.05 \\
\hline $22: 5 n-6$ & $0 \cdot 12$ & 0.04 & $0.08^{*}$ & 0.05 & 0.05 & 0.02 & 0.05 & 0.02 & 0.05 & 0.02 & 0.07 & 0.04 & 0.05 \\
\hline $18: 3 n-3$ & 0.66 & 0.19 & 0.59 & 0.12 & 0.73 & 0.38 & 0.63 & 0.15 & 0.71 & 0.11 & 0.88 & 0.28 & 0.05 \\
\hline $20: 5 n-3$ & 0.04 & 0.02 & 0.03 & 0.01 & $0.06^{*}$ & 0.02 & 0.05 & 0.02 & 0.05 & 0.01 & 0.06 & 0.02 & 0.05 \\
\hline $22: 5 n-3$ & 0.26 & 0.08 & $0.16^{*}$ & 0.04 & 0.12 & 0.06 & $0 \cdot 15$ & 0.04 & 0.14 & 0.03 & 0.16 & 0.08 & 0.05 \\
\hline $22: 6 n-3$ & 0.51 & 0.12 & $0.30^{*}$ & 0.09 & 0.25 & 0.07 & 0.28 & 0.08 & 0.25 & 0.11 & 0.34 & $0 \cdot 18$ & 0.05 \\
\hline Saturated & 38.06 & $5 \cdot 19$ & 39.45 & 3.95 & 38.89 & $4 \cdot 17$ & $43 \cdot 31^{*}$ & $6 \cdot 38$ & $42 \cdot 81$ & 3.71 & 42.06 & 3.07 & 0.05 \\
\hline Monounsaturated & 45.04 & 4.92 & $47 \cdot 38$ & 3.15 & $46 \cdot 38$ & 3.90 & $42.45^{\star}$ & 4.87 & 42.03 & $3 \cdot 36$ & 41.73 & $3 \cdot 20$ & 0.05 \\
\hline Polyunsaturated & $16 \cdot 90$ & 1.86 & $13 \cdot 17^{*}$ & $1 \cdot 89$ & 14.73 & $2 \cdot 20$ & $14 \cdot 24$ & $2 \cdot 26$ & $15 \cdot 16$ & 3.91 & $16 \cdot 21$ & 3.36 & 0.05 \\
\hline$n-3 / n-6$ & 0.10 & 0.02 & 0.09 & 0.02 & 0.09 & 0.03 & 0.09 & 0.02 & 0.09 & 0.02 & 0.15 & 0.07 & 0.05 \\
\hline
\end{tabular}

Mean values were significantly different from that at preceding time point: ${ }^{*} P<0.05$ (Fisher post-hoc test).

our present study we found changes in the milk FA percentage levels similar to those previously reported (Gibson \& Kneebone, 1981; Clark et al. 1982; Boersma et al. 1991; Luukkainen et al. 1994; Makrides et al. 1995). There is a mild progressive increase of the saturated FA coupled with a parallel decrease of the monounsaturated FA, the major changes being during the 3-6 month period, while total polyunsaturated $\mathrm{FA}$ remain almost stable throughout

Table 6. Daily intakes of lipids and long-chain polyunsaturated fatty acids from colostrum and mature hindmilk

(Median values and ranges for ten subjects)

\begin{tabular}{|c|c|c|c|c|c|c|}
\hline & \multicolumn{2}{|c|}{ Colostrum (1 d) } & \multicolumn{2}{|c|}{1 month } & \multicolumn{2}{|c|}{3 months } \\
\hline & Median & Range & Median & Range & Median & Range \\
\hline $\begin{array}{l}\text { Infant weight }(\mathrm{kg}) \\
\text { Daily milk volume (ml) }\end{array}$ & & $\begin{array}{c}2.80-3 \cdot 95 \\
70-350\end{array}$ & & $\begin{array}{c}3 \cdot 28-4 \cdot 67 \\
390-710\end{array}$ & & $\begin{array}{c}5 \cdot 98-7 \cdot 70 \\
535-820\end{array}$ \\
\hline $\begin{array}{l}\text { Total lipids }(\mathrm{g} / \mathrm{kg}) \\
\text { Cholesterol }(\mathrm{mg} / \mathrm{kg}) \\
\text { Phospholipids }(\mathrm{mg} / \mathrm{kg})\end{array}$ & $\begin{array}{r}1 \cdot 07 \\
10 \cdot 49 \\
14 \cdot 73\end{array}$ & $\begin{array}{l}0 \cdot 22-3 \cdot 73 \\
2 \cdot 44-21 \cdot 19 \\
3 \cdot 31-51 \cdot 67\end{array}$ & $\begin{array}{c}5.83 \dagger \\
13.81 \\
78.03 \dagger\end{array}$ & $\begin{array}{c}4 \cdot 37-7 \cdot 50 \\
8 \cdot 22-21 \cdot 93 \\
51 \cdot 39-138 \cdot 27\end{array}$ & $\begin{array}{l}4.48 \dagger \\
11.53 \\
41.33 \dagger\end{array}$ & $\begin{array}{c}2 \cdot 65-11 \cdot 77 \\
6 \cdot 72-14 \cdot 44 \\
29 \cdot 07-120 \cdot 01\end{array}$ \\
\hline $\begin{array}{l}18: 2 n-6(\mathrm{mg} / \mathrm{kg}) \\
18: 3 n-6(\mathrm{mg} / \mathrm{kg}) \\
20: 3 n-6(\mathrm{mg} / \mathrm{kg}) \\
20: 4 n-6(\mathrm{mg} / \mathrm{kg})\end{array}$ & $\begin{array}{r}142.7 \\
0.72 \\
7.45 \\
11.29\end{array}$ & $\begin{array}{l}49 \cdot 9-502 \cdot 6 \\
0 \cdot 11-3 \cdot 62 \\
2 \cdot 39-23 \cdot 21 \\
4 \cdot 21-48 \cdot 39\end{array}$ & $\begin{array}{r}354 \cdot 1 \dagger \\
4 \cdot 17 \dagger \\
18.58 \dagger \\
24.05^{\star}\end{array}$ & $\begin{array}{c}253.3-646.9 \\
2.87-7.93 \\
14.47-29.04 \\
16.84-31.54\end{array}$ & $\begin{array}{c}351.3 \dagger \\
3.43 \dagger \\
11.16 \dagger \\
15.92\end{array}$ & $\begin{array}{c}272 \cdot 1-854 \cdot 5 \\
2.29-6 \cdot 64 \\
8.96-17 \cdot 60 \\
9 \cdot 33-31 \cdot 97\end{array}$ \\
\hline $\begin{array}{l}18: 3 n-3(\mathrm{mg} / \mathrm{kg}) \\
20: 5 n-3(\mathrm{mg} / \mathrm{kg}) \\
22: 5 n-3(\mathrm{mg} / \mathrm{kg}) \\
22: 6 n-3(\mathrm{mg} / \mathrm{kg})\end{array}$ & $\begin{array}{l}8.27 \\
0.43 \\
3 \cdot 14 \\
6.81\end{array}$ & $\begin{array}{l}1.39-28.16 \\
0.09-2.04 \\
0.64-7.36 \\
1.85-16.23\end{array}$ & $\begin{array}{r}20.90 \dagger \\
1.85 \dagger \\
6 \cdot 08^{*} \\
11.74^{*}\end{array}$ & $\begin{array}{c}12.36-29.55 \\
0.80-3.54 \\
3.29-8.56 \\
4.45-16.36\end{array}$ & $\begin{array}{c}18.54 \dagger \\
1.49 \dagger \\
3.97 \\
7.31\end{array}$ & $\begin{array}{c}11.69-43.45 \\
1.06-2 \cdot 80 \\
0.52-8 \cdot 19 \\
4.28-11.75\end{array}$ \\
\hline
\end{tabular}


nursing after the colostrum time point. However, compared with data previously reported in an exhaustive review (Koletzko et al. 1992), our findings show a higher percentage of monounsaturated FA which could be related to the consumption of olive oil, rich in oleic acid, traditional in the Italian diet. It is of interest that the major long-chain polyunsaturated FA show their highest percentage levels at colostrum and then abruptly decrease at 1 month to levels subsequently maintained throughout the nursing period.

As to the lipid concentrations $(\mathrm{mg} / \mathrm{dl})$ in milk, total fat (99\% triacylglycerols in mature milk; Jensen, 1996) shows a rapid increase and then a substantial stability from the third month onwards. These changes may be related to the high energy requirements of the growing infants. The modifications of the cholesterol: total lipid and phospholipid: total lipid ratios confirm published data (Herzer et al. 1983) and are consistent with the temporal changes in milk-fat globules, whose total surface area decreases in progressing lactation. Since the surface area is directly related to the amount of membrane material surrounding the fat droplets, mainly including phospholipids and cholesterol, it follows that the relative phospholipid and cholesterol contents are lower in mature milk (Ruegg \& Blanc, 1981).

Considering the concentrations $(\mathrm{mg} / \mathrm{dl})$ of the individual FA, there is a two-threefold increase of the C18 unsaturated FA, parallel to that of total fat, during the first stages of lactation. However the concentrations of the major longchain polyunsaturated FA (particularly of 22:6n-3) remain almost stable throughout lactation, even if the total fat content clearly increases from colostrum up to 3 months. Thus the absolute quantities of long-chain polyunsaturated FA supplied to the suckling infants does not appear to depend only on the absolute amounts of fat provided by milk. This observation requires further investigation to elucidate the regulatory mechanisms of $20: 4 n-6$ and $22: 6 n-3$ secretion into human milk.

As a result of the changes in body weight and the progressively higher milk-fat content and higher milk intake coupled with the stability of the milk long-chain polyunsaturated FA content, the intakes $(\mathrm{mg} / \mathrm{kg})$ of $20: 4 n-6$ and $22: 6 n-3$ increase from colostrum up to 1 month with some reduction later on, reaching values at 3 months similar to the initial ones. This trend is mainly due to the change in the milk volume : infant weight ratio occurring during the second and the third month of lactation. The intakes $(\mathrm{mg} / \mathrm{kg})$ of $18: 2 n-6$ and $18: 3 n-3$ increase about 2.5-times between colostrum and 1 month maintaining a very constant ratio (about 17:1), and remain stable up to 3 months. On the whole, the 20:4n-6 and 22:6 n-3 intakes (mg/kg) change less than those of the two $\mathrm{C} 18$ precursors between the stages of colostrum and more mature human milk, but their levels are similar to those at colostrum, at the end of exclusive breast-feeding. These changes may be associated with the development of the polyunsaturated FA metabolic pathway, as suggested also by the marked increment of $18: 3 n-6$, the product of $\Delta 6$ desaturation, and the reduction of $20: 2 n-6$, the product of linoleic acid elongation, a minor alternative pathway in the $n-6$ series. In addition, the brain growth in the first 4 weeks of life occurs at a rate similar to the incorporation of long-chain polyunsaturated FA (Clandinin et al. 1980). The constant intake of high levels of C18 precursors by the infant from mature milk may be, however, a marker of their dietary essentiality.

Even correcting for the higher average lipid content of hindmilk, the meaning of our observations does not change, due to the rather constant composition of human milk during a single feeding. According to our findings, breast-fed babies receive fats varying in quantity and quality. Since most studies in the literature focus only on the percentage FA composition of human milk, our data suggest that the absolute amounts of fats and individual FA in human milk provide useful information also for optimizing formulas for artificial feeding.

\section{Acknowledgements}

The study was supported by the Danone Institute of Italy.

\section{References}

Agostoni C, Trojan S, Bellù R, Riva E \& Giovannini M (1995) Neurodevelopmental quotient of healthy term infants at 4 months and feeding practice: the role of long-chain polyunsaturated fatty acids. Pediatric Research 38, 262-266.

Boersma ER, Offringa PJ, Muskiet FJ, Chase WM \& Simmons IJ (1991) Vitamin E lipid fractions, and fatty acid composition of colostrum, transitional milk, and mature milk: an international comparative study. American Journal of Clinical Nutrition 53, 1197-204.

Central Statistics Institute (ISTAT) (1983) Twelfth General Census of the Italian Population Rome. Rome: ISTAT.

Clandinin MT, Chappell JE, Leong S, Heim T, Swyer PR \& Chance GW (1980) Extrauterine fatty acid accretion in infant brain: implications for fatty acid requirements. Early Human Development 4, 131-138.

Clark RM, Ferris AM, Brown PB, Hundrieser KE \& Jensen RG (1982) Changes in the lipids of human milk from 2 to 16 weeks postpartum. Journal of Pediatric Gastroenterology and Nutrition 1, 311-315.

Farquharson J, Cockburn F, Patrick WA, Jamieson EC \& Logan RW (1992) Infant cerebral cortex phospholipid fatty-acid composition and diet. Lancet 340, 810-813.

Folch J, Lees M \& Sloane-Stanley GH (1956) A simple method for isolation of total lipides from human tissues. Journal of Biological Chemistry 226, 497-509.

Gibson RA \& Kneebone GM (1980) Effect of sampling on fatty acid composition of human colostrum. Journal of Nutrition 110, 1671-1675.

Gibson RA \& Kneebone GM (1981) Fatty acid composition of human colostrum and mature breast milk. American Journal of Clinical Nutrition 34, 252-257.

Herzer G, Haug M, Dieterich I \& Gentner PR (1983) Changing patterns of human milk lipids in the course of the lactation and during the day. American Journal of Clinical Nutrition 37, 612621.

Jensen RG (1996) The lipids in human milk. Progress in Lipid Research 35, 53-92.

Jensen RG, Ferris AM, Lammi-Keefe CJ \& Henderson RA (1990) Lipids of bovine and human milk: A comparison. Journal of Dairy Sciences 73, 233-240.

Koletzko B (1997) Lipid supply for infants with special needs. European Journal of Medical Research 2, 69-73.

Koletzko B, Mrotzek M \& Bremer HJ (1986) Fat content and cisand trans- isomeric fatty acids in mature human fore- and hindmilk. In Human Lactation 2: Maternal and Environmental Factors, pp. 589-594 [M Hamosh and AS Goldman, editors]. New York, NY: Plenum Press. 
Koletzko B, Thiel I \& Abiodun PO (1992) The fatty acid composition of human milk in Europe and Africa. Journal of Pediatrics 120, S62-S70.

Lucas A, Morley R, Cole TJ, Lister G \& Leeson Pajne J (1992) Breast milk and subsequent intelligence quotient in children born preterm. Lancet 63, 1382-1385.

Luukkainen P, Salo MK \& Nikkari T (1994) Changes in the fatty acid composition of preterm and term human milk from 1 week to 6 months of lactation. Journal of Pediatric Gastroenterology \& Nutrition 18, 355-360.

Makrides M, Simmer K, Neumann M \& Gibson R (1995) Changes in the polyunsaturated fatty acids of breast milk from mothers of full-term infants over 30 weeks of lactation. American Journal of Clinical Nutrition 61, 1231-1233.
Pisani P, Faggiano F, Krogh V, Palli D, Vineis P \& Berrino F (1997) Relative validity and reproducibility of a food frequency dietary questionnaire for use in the Italian EPIC centres. International Journal of Epidemiology 26, Suppl. 1, S152S160.

Rouser G, Skiatos AN \& Fleischer S (1966) Quantitative analysis of phospholipids by thin layer chromatography and phosphorus analysis of spots. Lipids 1, 85-86.

Ruegg M \& Blanc B (1981) The fat globule size distribution in human milk. Biochimica et Biophysica Acta 666, 7-14.

Trevisan M, Krogh V, Ferro-Luzzi A, Riccardi G, Freudenheim J, Sette S \& Scaccini C (1992) Food questionnaire for epidemiological studies on large cohorts for use in Italy. Annali dell'Instituto Superiore de Sanità 28, 397-401. 